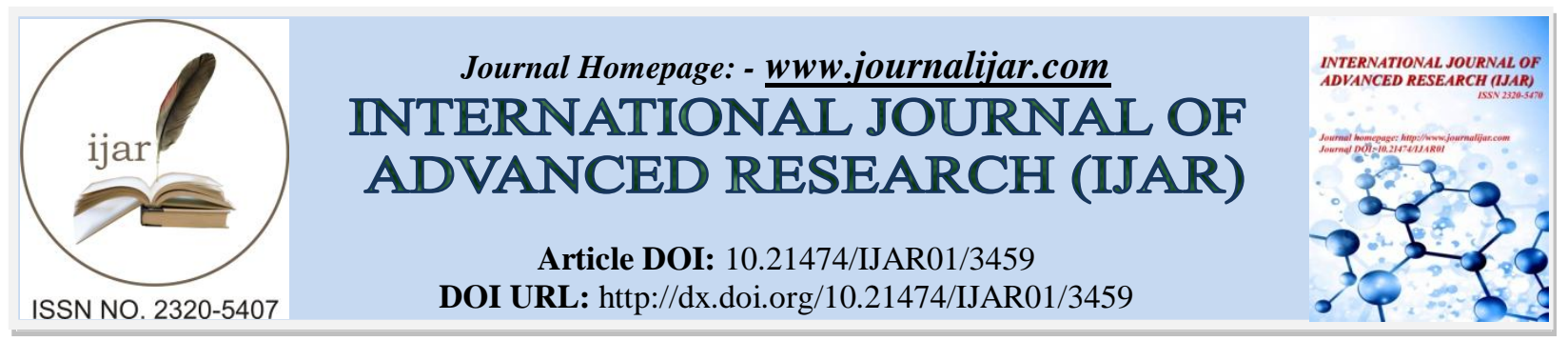

RESEARCH ARTICLE

\title{
EFFICACY OF VACCUM ASSISTED CLOSURE IN THE TREATMENT OF ULCERS OF LOWER LIMB.
}

Dr. Saurabh Agarwal ${ }^{1}$ and Dr.Viswanath Atreyapurapu ${ }^{2}$.

1. Associate professor Department of General Surgery Himalayan institute of medical sciences, Doiwala, Dehradun.

2. Senior resident Department of General Surgery ASRAMS,Eluru.

\section{Manuscript Info}

............................

Manuscript History

Received: 19 December 2016

Final Accepted: 17 January 2017

Published: February 2017

Key words:-

NPWT-negative pressure wound therapy.

\section{Abstract}

Introduction: Vacuum Assisted Closure(VAC), sometimes referred to as Micro Deformational Wound Therapy (MDWT) or Negative Pressure Wound Therapy,has revolutionized the way wounds are treated over the last decade ${ }^{1}$.

AIM: To study and compare number of secondary amputations and number of debridements required between $\mathrm{VAC}$ and conventional moist dressing.

Material and Methods: 30patients were selected.VAC was applied in 15 patients and changed every $3^{\text {rd }}$ day and conventional dressings was done in 15 patients and dressings were changed twice daily.

Results: Number of secondary amputations and debridements has significantly reduced in Vac therapy than conventional.

Conclusions: Use of $\mathrm{Vac}$ in our study led to significant results and better outcome.

Copy Right, IJAR, 2017,. All rights reserved.

\section{Introduction:-}

In 1993,Fleschman et al., first documented the use of sub-atmospheric pressure to manage chronic wounds ${ }^{2}$.Argenta expanded this method by publishing a clinical report on effect of NPWT on complicated wounds ${ }^{3}$.It works on the principle of application of micromechanical forces that promote wound healing ${ }^{4,5}$.

In sepearte studies,Saxena et $\mathrm{al}^{6}$ and Greece et al. ${ }^{7}$ have further elucidated the role of open pore foam dressing in the creation of micromechanical deformations of the wound surface. These microdermal deformations are caused when negative pressure draws tissue into the foam pores. This stretches cells and promotes cell division that stimulates granulation tissue formation ${ }^{6}$. The rate of granulation tissue is faster in the later setting than the former ${ }^{8}$.

VAC dressings should be changed every 2-3days. This hasten the wound healing by a)increasing the rate of growth of granulation tissue,b)stimulating proliferation of capillaries(angiogenesis),c)increasing local blood flow, d)applying mechanical pressure to promote wound closure.e)reducing bacterial load in the wound,f)suctioning matrix metalloproteinase in wound credentials,g)maintains a moist micro environment, beneficial for wound closure. $9,10,11$,

Corresponding Author:- Dr. Saurabh Agarwal.

Address:- Associate professor Department of General Surgery Himalayan institute of medical sciences, Doiwala ,Dehradun. 
Wound healing is the summation of a number of processes that follow injury ${ }^{12}$. The same events, in the same order,occur in every healing process in all the tissues. Duodenal ulcers, myocardial infections, cellulitis, long bone fractures,surgical incisions and traumatic wounds all undergo the same reparative processes ${ }^{13}$.

\section{Sequence of healing process:-}

1. Inflammatory phase or reactive phase(1-6weeks).

2. Proliferative phase or regenerative phase(2weeks- 2years).

3. Maturational phase or remodeling phase(6months- 2years).

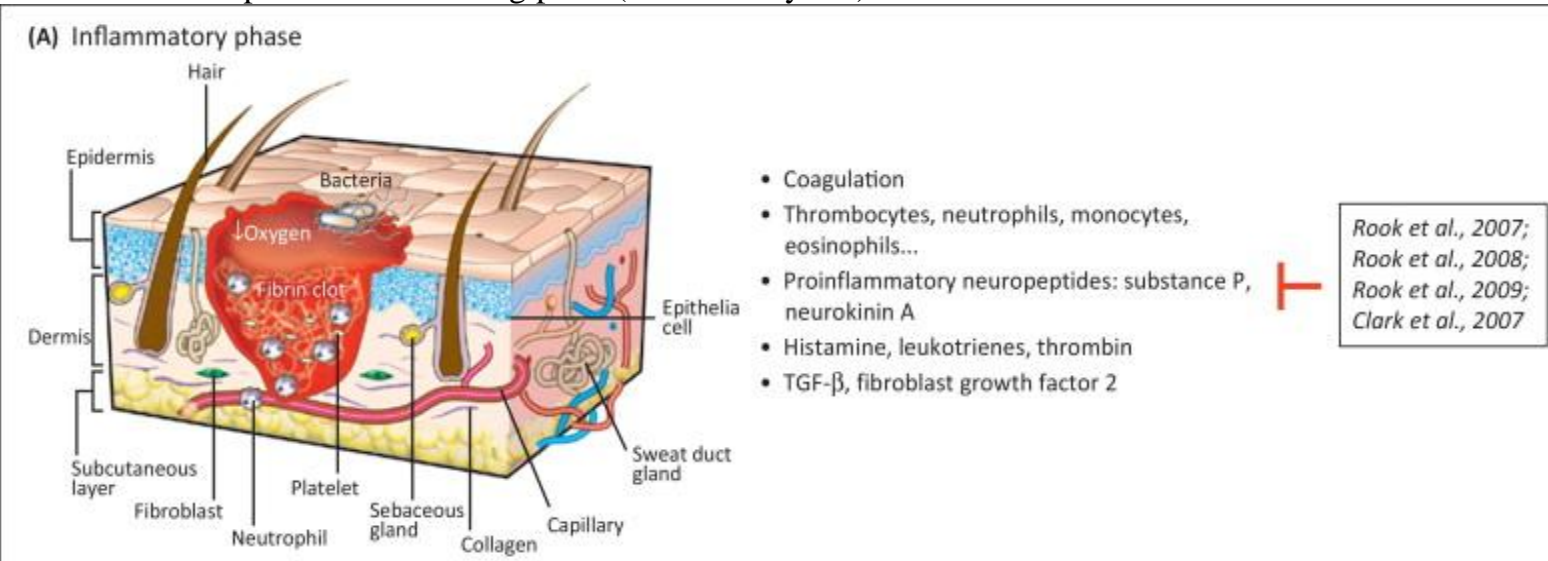

(B) Proliferative phase/reepithelization

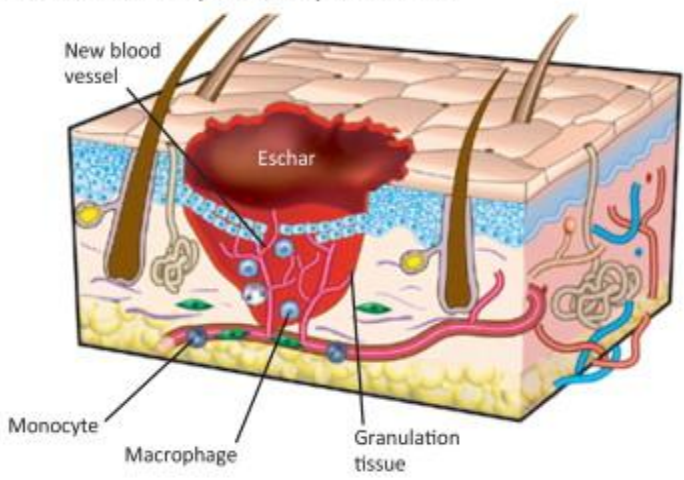

- Keratinocyte migration, reepithelization

- FGF- $2,-7,-10$

- Matrixmetalloproteinase (MMP) 1

- Collagen synthesis, angiogenesis

- Granulation tissue: fibroblasts

- Hypoxia-induced factor (HIF)-1 $\alpha$, VEGF A, FGF-2

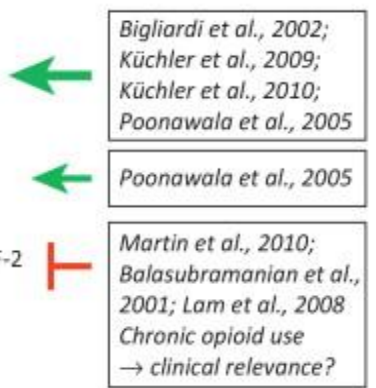

(C) Maturation

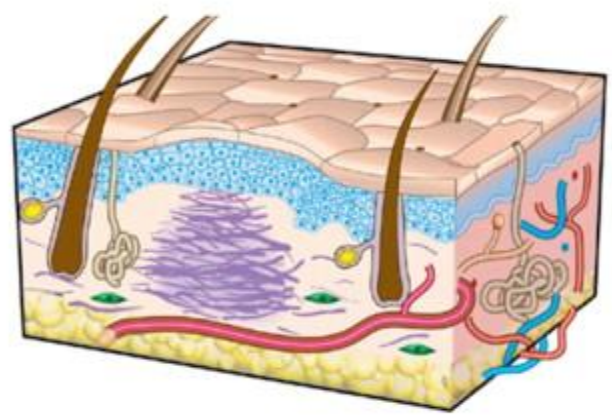

- Myofibroblasts $\rightarrow$ wound contraction

- Platelet-derived growth factor (PDGF), TGF- $\beta$

- MMP-2, MMP-7

Clinical factors affecting wound healing ${ }^{13,14,15}$ 


\section{Local factors:-}

Infection,presence of necrosis,foreign body,site of wound-excess local morbidity (such as over the joint), venous and lymph stasis due to poor drainage,recurrent trauma,inadequate blood supply,poor surgical apposition,wound dehiscence.

\section{General factors:-}

elderly age,hypoxemia-anemia, hypovolemia,shock of any cause,coronary heart disease leading to peripheral shut down,congestive heart failure causing odema and fluid over load,C.O.P.D causing reduced $\mathrm{O}_{2}$ saturation of the blood,acute respiratory disease such as pneumonia,malnutrition,diabetis with poor glycemic control,immunodeficiency,obesity and smoking.

Chronic leg ulcers ${ }^{14,15,16,17,18}$

A chronic leg ulcer is a loss of skin below the knee on the leg or foot which takeslonger than 6weeks to heal despite of standard treatment of underlying disease and local wound care.However the SIGN(1998) guidelines consider 4weeks to be definitive.

Complications of $\operatorname{vac}^{6}:-$

Common complications include bleeding, infection,pain,foam retention within the wound,tissue adherence.other less complication include hypergranulation.

\section{Aim:-}

To compare the efficacy of VAC over regular conventional dressing.

EFFICACY includes:number of debridements required and the number of secondary amputations required and graft uptake.

\section{Materials and Method:-}

Out of 60 pateints presenting with ulcer over a period of 5 months, 30 patients were selected.

Criteria for exclusion:Patients with malignant ulcers, with venous ulcers, with peripheral arterial occlusive disease, with ICU stay, with ulcers greater than $15 \mathrm{~cm}$ size in largest dimension,with more than one ulcer,with chemical burns, charcot`s disease.

In experimental group after surgical debridement, simplified VAC was applied and changed every 3 day.

In control group saline soaked guaze dressings were applied at the time of surgical debridement and changed twice daily.

\section{Method:-}

VAC - procedure

- Placing a sterile,polyurethane foam dressing,into the wound defect after it has been trimmed to shape.

- Adhesive drape was used to cover the foam and additional 3 to $5 \mathrm{~cm}$ of surrounding intact skin.

- A slit measuring 1 to $2 \mathrm{~cm}$ long was created in the drape -it acted as the diameter of the circular hole which was cut in the drape.The non-collapsible tube was placed directly over the hole in the drape and connected to the elctronic vacuum pump.

- Finally,negative pressure was applied to the wound via the therapy unit,causing the dressing to collapse into the wound.

- A standard negative pressure of $-125 \mathrm{~mm}$ of hg was applied to the wound,continuously.

- Change of dressing was performed every 48 to 96 hours in the ward for the patient by a trainedtechnician from $\mathrm{KCI}$ wound care in the presence of doctor/nurse. 


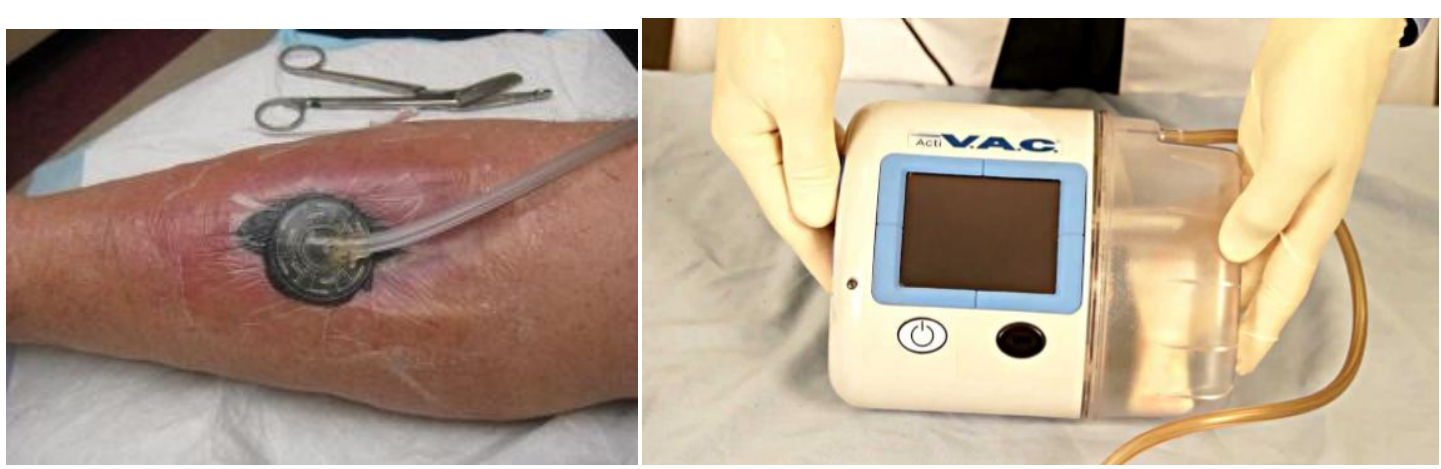

\section{Conventional dressings:-}

- Conventional dressing used cleansing of wound with hydrogen peroxide or normal saline and application of betadine.

- Wound dimensions were measured with a ruler. Examination was done on the day following first debridement for control and on the day of application of VAC for study group.Graft uptake was assessed on the day of discharge.

\section{Factors Assessed:-}

Number of redebridements that followed.

Number of amputations that followed.

Graft uptake.

Data analysis:A t-test was used to compare means of variables in between the groups and z-test used to compare proportions.

A p value of 0.05 was used to determine statistical significance.

\section{Results:-}

Number of total cases: 60

Cases included in the study: 30

\section{Amputations:-}

\section{amputations}

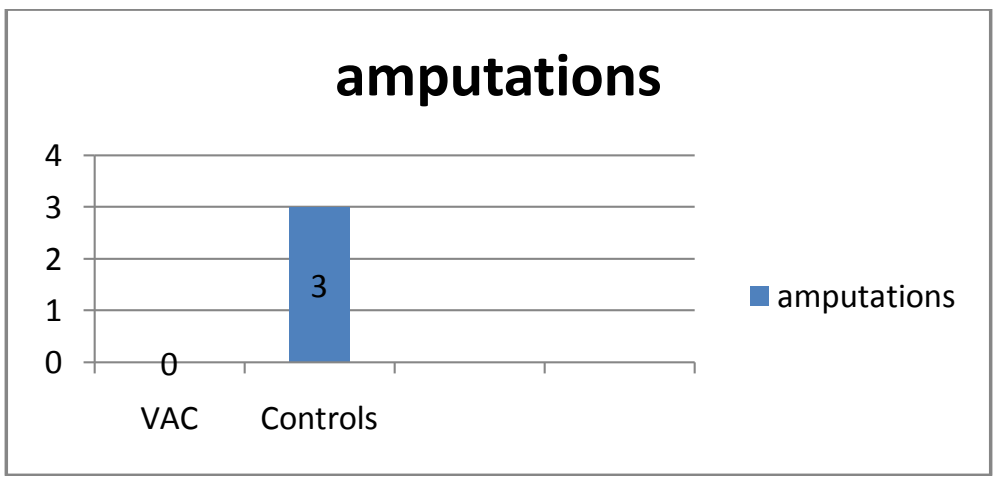

$\mathrm{p}=0.0378$

3 patients in control group had to undergo amputations in the lower limb whereas none of the patients in VAC had to undergo amputation. 


\section{Graft uptake:-}

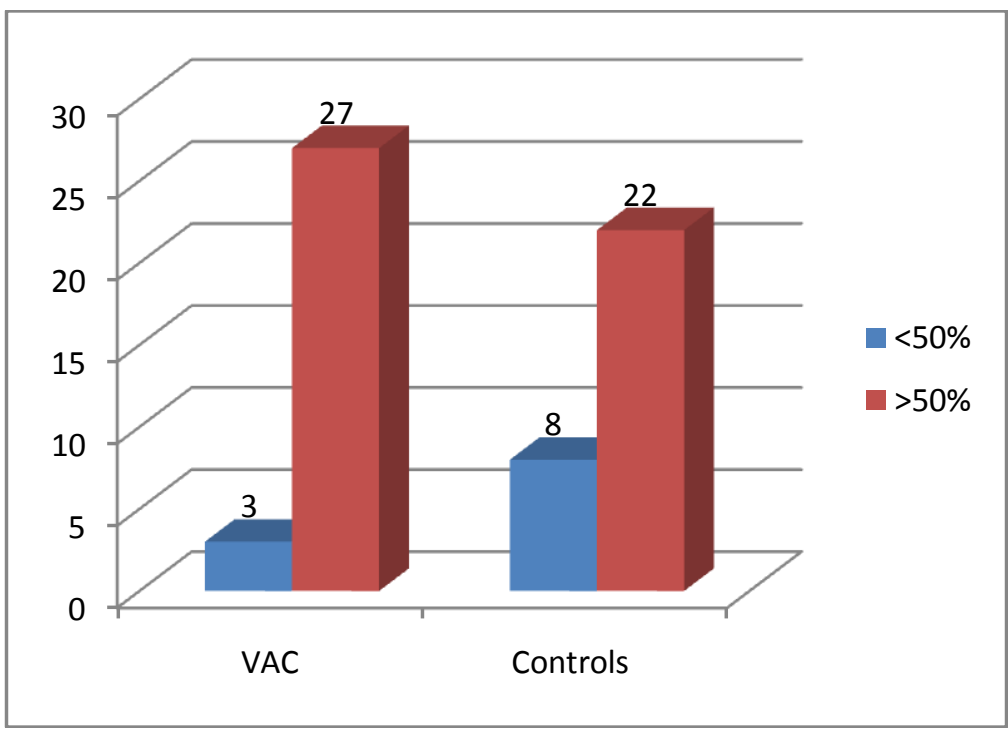

In 27 patients in VAC group and 22 patients in control group had graft uptake of more than $50 \%$.

\section{Redebridements:-}

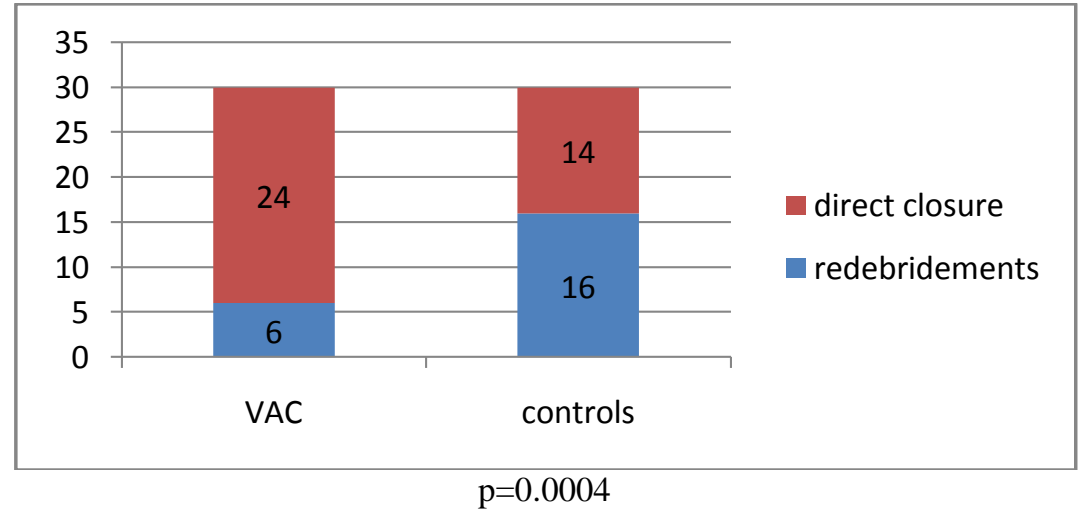

6 patients in VAC group had to undergo a second debridement following application of VAC where as 16 patients in control group had undergo a second debridement.

\section{Discussion:-}

- Vac therapy resulted in significant reduction in number of amputations.

- Vac therapy resulted in statistically significant improvement in graft uptake.

- Vac therapy resulted in significant reduction in number of surgical debridements.

\section{Comparision with other studies:-}

A randomized control study by Ali et al $(2014)^{19}$ concluded that VAC therapy results in faster appearance of granulation and fewer amputation,a conclusion similar to our study.

A multicentre randomized control study by Blume et $\mathrm{al}^{20}$ concluded that Vac therapy results in reduced amputations, a conclusion similar to our study.

Demerits:The difference in the wound characters were not studied at histopathological level.Study has observer bias as it is not a blinded study. 


\section{Conclusion:-}

The efficacy of NPWT in promoting healing of ulcers of lower limb has been largely accepted by clinicians.we believe that advances in mechanobiology, the science of wound healing,the understanding of biofilms, and advances in cell therapy will lead to better care of our patients.

\section{Bibliography:-}

1. Huang, Chenyu et al. :Effect of negative pressure wound therapy on wound healing ,Current Problems in Surgery, Volume51,Issue 7, 301-331.

2. Fleischmann W,Strecker W,Bombelli M,et al.Vacuum sealing as treatment of soft tissue damage in open fractures.Unfallchirurg.1993;96:488-492.[PubMed]

3. Argenta LC,Morykwas MJ.Vacuum assisted closure;a new method for wound control and treatment:clinical experience.Ann PlastSurg.1997;38:563-577.[PubMed]

4. S.S. Scherer,G.Pietramaggioori,J.C.Mathews,M.J Prsa,S.Huang and D.P.Orgill,The Mechanism of action of the Vacuum-Assisted Closure Device,Plastic surgery and Reconstructive Surgery,Vol.122,No. 3,2008,pp.786-797.

5. Morykwas MJ, Argenta LC,Shelton-brown El, et al.vacuum-assisted closure:a new method for wound control and treatment: animal studies and basic foundation.Ann PlastSurg.1997;38:553-562.[PubMed].

6. Saxena V,Hwang CW,Huang S,Eichbaum Q,Ingber D, Orgill DP:Vacuum assisted closure:microdeformations of wounds and cell proliferation.Plast Reconstr Surg 114: 1086-1096,2004.

7. Greene AK,Puder M,Roy R,Arsenault D,Kwei S,Moses MA,Orgill DP:Microdeformational wound therapy: effects on angiogenesis and matrix metalloproteinases in chronic wounds of 3 debilitated patients. Ann Plast Surg56:418-422,2006.

8. V.A.C Therapy clinical Guidelines.A Reference Source for Clinicians.KCI,San Antonia,TX;2004.

9. Morykwas MJ,Simpson J,Punger K,Argenta A,kremers L,Argenta J.vacuum-assisted closure:state of basic research and physiologic foundation. plastReconstrSurg 2006;117:121S-126S.

10. greene Ak,puder M,Roy R et al.Microdeformational Wound Therapy:Effects on Angiogenesis and Matrix Metalloproteinases in Chronic wounds of 3 Debilitated Patients.Ann PlastSurg 2006;56:418-422.

11. Weed T,Ratliff C,Drake Db.Quantifying bacterial bioburden during negative pressure wound therapy: does the wound VAC enhance bacterial clearance?Ann PlastSurg.2004;52:276-279.[PubMed]

12. David J Coleman:Wounds, tissue repairs,scars;Short practice of Surgry Bailey and Love $24^{\text {th }}$ edition,2004,

13. 84-89.

14. Mimi Leong and Linda G Philips:Wound healing ; Sabiston textbook of Surgery, The biological basis of modern surgical practice, $17^{\text {th }}$ edition,WB Saunders, 2001; 183-207.

15. Joseph E Grey,Stuart Enoch,Keith G Harding: ABC of wound healing,wound assessment,BMJ Vol 332(4), February 2006.

16. Georgina Casey:Causes and management of leg and foot ulcers,Nursing Standard,Vol 18(45),21 July 2004,

17. 57-64.

18. Functional Anatomy of Leg and Foot,an online lecture by Mark R Forwood,Department of Anatomical sciences,Functional anatomy, The university of Queensland.

19. http://www.bartleby.com/IV_Myology_8c_The muscles and fascia of the leg_Gray,henry_1918_Anatomy of the human Body.htm.

20. Ronald A Bergman,Adel K Affi,Jean J Jew,Paul C Reimann:Atlas of Human anatomy in cross section: Section 7.Lower limb,anatomy atlases, A digital library of anatomy information, www. anatomyatlases. org $/ \mathrm{croo} 7 . \mathrm{htm}$.

21. LONE,A.,ZAROO,M.,LAWAY ,B.,PALA,N.,BASHIR, S.,RASOOL, A..Vacuum-assisted closure versus conventional dressings in the management of diabetic foot ulcer prospective case-control study.Diabetic Foot\& Ankle,North America,5,apr.2014.

22. Blume $\mathrm{PA}^{1}$,Walters J,Payne W,Ayala J,Lantis J.Comparison of negative pressure wound therapy using vacuumassisted closure with advanced moist therapy in the treatment of diabetic foot ulcers: a multicenter randomized controlled trial Diabetics Care.2008 Apr;31(4):631-6. Epub 2007 Dec27. 